\title{
Closing the Gap: the need to consider perceptions about drinking water in rural Aboriginal communities in NSW, Australia
}

\author{
Fidelis G Jaravania,d, Peter D Masseya ${ }^{a}$ Jenni Judd ${ }^{\mathrm{b}}$, Jason Allanc \\ and Natalie Allan ${ }^{\mathrm{a}}$
}

a Health Protection, Hunter New England Population Health, Newcastle, NSW, Australia

b Division of Tropical Health and Medicine, James Cook University, Townsville, Queensland, Australia

- Walhallow Local Aboriginal Land Council, Caroona, NSW, Australia

${ }^{d}$ Corresponding author: fidelis.jaravani@hnehealth.nsw.gov.au

\section{Article history}

Publication date: April 2016

Citation: Jaravani FG, Massey PD, Judd J, Allan J, Allan N. Closing the Gap: the need to consider perceptions about drinking water in rural Aboriginal communities in NSW, Australia. Public Health Res Pract. 2016;26(2):e2621616. doi: http://dx.doi. org/10.17061/phrp2621616

\section{Key points}

- Water plays a vital role in the cultural, spiritual, emotional and physical wellbeing of rural Aboriginal communities

- Provision of drinking water may be futile without appreciating the unique cultural, historical and socioeconomic factors associated with Aboriginal communities

- A new perspective on drinking water is needed by public health authorities and drinking water providers to actively engage with the communities they service

- Reducing public health risk due to drinking water of unknown quality will help to close the gap between Indigenous and non-Indigenous Australians' morbidity and mortality rates

\section{Abstract}

A crucial objective of the Australian Government's Closing the Gap program is to improve Aboriginal health, and to achieve morbidity and mortality rates similar to those for non-Indigenous Australians. Reducing public health risks due to drinking water of unknown quality will help to close the gap.

Factors such as hardness, taste, colour and odour of water may influence perceptions of risk and quality. Increased contact and familiarity with a hazard is associated with individuals becoming desensitised and habituated to its presence, so that their risk judgements may reflect their behavioural experiences. Consumption of water of unknown quality, such as rainwater, instead of treated town water in Australian Aboriginal communities may be a community norm, a part of a community's culture or a result of lack of trust in government water suppliers.

Partnerships between service providers and communities can ensure that the service is responsive to community needs, is conducted in a culturally appropriate manner and is beneficial to the community. Governance of drinking water in Aboriginal communities cannot be comprehensive without active engagement of the communities involved, and greater understanding of cultural issues, perceptions and behaviours towards drinking water quality. This Perspective article reviews the literature to shed light on the need to consider New South Wales (NSW) Aboriginal perceptions about drinking water and its acceptability. We urge more dialogue and research, and a policy focus that includes partnerships with discrete NSW Aboriginal communities to develop a deeper understanding of perceptions of drinking water and encourage consumption of safe water. 


\section{Introduction}

The need for access to safe drinking water is an important ongoing public health issue globally, including in rural areas of Australia. ${ }^{1}$ Poor water supply and sanitation contribute to a higher incidence of many diseases, including diarrhoeal disease, acute respiratory infection, skin infection and hepatitis B. ${ }^{2}$

Aboriginal people, especially in rural Australia, have ongoing strong connections to water, with water playing a vital role in communities' cultural, spiritual, emotional and physical wellbeing. ${ }^{3}$ Reports discussing Aboriginal traditional stories relating to water highlight the importance of water to Aboriginal people. Beliefs and ideas associated with water can be linked to the beliefs of Aboriginal people about how the world attained its present form and shape ${ }^{2}$, and Indigenous communities understand that water has spiritual and living attributes. Water is valued not only for what it can provide humans, but also for what it is in itself. ${ }^{4}$

Aboriginal communities' strong connection to water can mean that the provision of drinking water may be futile without an appreciation of the unique cultural, historical and socioeconomic characteristics of communities. ${ }^{1}$ Concerns about the safety and quality of drinking water may also be a proxy for other social and community concerns.

This Perspective article is a review of the literature to highlight the need to consider New South Wales (NSW) Aboriginal perceptions about drinking water and its acceptability. We encourage more dialogue, research and a policy focus that includes partnerships with discrete NSW Aboriginal communities to develop a deeper understanding of community perceptions about drinking water.

\section{Recognition of Aboriginal values}

A key step in improving water governance in Aboriginal communities is to ensure that Aboriginal people's values and interests about water are better recognised and more clearly incorporated in decision making processes. ${ }^{5}$ In the past, Australia has not systematically incorporated community views and knowledge on issues concerning management of water demand, development of water sources and water allocation. ${ }^{6}$ Australia's approach to access to water for Indigenous people appears to be inconsistent, ad hoc and underdeveloped. Australia is one of only two member states of the Organisation for Economic Co-operation and Development that have not acceded to the World Health Organization's recommendation that all countries have national, legally binding standards for drinking water quality. ${ }^{7}$ It has been argued that Aboriginal Australians are likely to face a higher degree of competition and contestation over water in the absence of a policy or legal framework that prioritises Aboriginal community rights and interests. ${ }^{8}$
However, the National Water Initiative represented a substantive change, and a step forward, by explicitly recognising Aboriginal communities' interests in water. ${ }^{9}$ The Initiative stresses that access to water for Aboriginal people should be achieved through a planning process that:

- Includes Aboriginal community representation in water planning

- Takes into account the possible existence of native title rights to water in the catchment and aquifer area

- Potentially allocates water to native title holders

- Accounts for any water allocated to native title holders for traditional purposes

- Incorporates Aboriginal social, spiritual and customary objectives and strategies for achieving these objectives. Such objectives include connections to secular and sacred water sources, emotional wellbeing, and rights to good health for individuals, families and communities.

These points emphasise environmental flow and Aboriginal access to water, but do not specifically consider the value of drinking water within the social, spiritual and customary objectives. An assessment of the impact of the National Water Initiative has reported a negligible effect on the distribution of water to Aboriginal people. ${ }^{8}$

\section{NSW Government initiatives}

The desire to provide safe and adequate drinking water to Aboriginal communities in NSW is evidenced by a number of programs, including:

- NSW Health's introduction of the Drinking Water Monitoring Program in 2001

- Improved support programs for drinking water quality management systems

- Establishment of the Aboriginal Communities Water and Sewerage Program

- The Housing for Health program

- Requirements of the NSW Public Health Act 2010 and Public Health Regulation 2012.

These programs are dedicated to monitoring drinking water and maintaining the water supply infrastructure to ensure safe, reliable and sustainable water supplies through the development of water quality assurance plans.

Since 2001, NSW Health has been monitoring public water supplies in discrete Aboriginal communities. Reports indicate that the water generally meets the microbiological standards of the Australian drinking water guidelines (2011). There have been no waterborne disease outbreaks or 'boil water' advisories due to drinking water contamination in NSW Aboriginal communities since 2001. However, many people with gastroenteritis may not seek medical attention, especially if the illness is minor and self-limiting. ${ }^{10}$ NSW drinking water monitoring data show that levels of nonhealth 
properties of water, such as total hardness and total dissolved solids, are high in most of the water systems. Water hardness may be the main reason that most communities prefer rainwater to reticulated supplies.

Have these programs and legislative developments changed the attitudes, behaviours and perceptions of Aboriginal consumers towards the acceptability of water supplies? The most probable answer is "no". It has been argued that throwing money at a problem without the money being guided by those who understand what is required will achieve little, and may even be counterproductive. ${ }^{7}$ In Camarines Sur, the Philippines, in 2012 , it was found that $77 \%$ of villagers who had access to chlorinated water chose to drink from untreated wells that were contributing to a cholera outbreak, despite the resulting increase in cases and deaths from the disease. ${ }^{11}$ Villagers only agreed to drink treated water after improved health education that took community perceptions, attitudes and behaviours into account.

Studies in Canada have indicated that people in First Nations communities often experienced greater health risks than those living in urban areas, despite government programs similar to the drinking water programs in NSW. ${ }^{12}$ Despite financial and technological investment, the governance and management structures did not appear to significantly reduce the gap in service standards. Choices about drinking water consumption are governed by a complex set of factors related to sensory perception; risk perception; and economic, psychological and social issues, including media reports and marketing messages. ${ }^{13}$ Walters and colleagues recommended exploring social or other underlying determinants of risk, such as community perceptions of the problem, to allow better mitigation of the risk. ${ }^{12}$

\section{Local Aboriginal knowledge}

Developing appropriate drinking water programs requires incorporating local Aboriginal knowledge into how drinking water is, and has been, provided in Aboriginal communities. Knowledge of how communities are socially and historically connected to drinking water, their reasons for valuing water, their perceptions of drinking water quality, and the degree of satisfaction with drinking water management and governance can shape people's behaviours and choices. ${ }^{14}$ Poor perceptions of drinking water safety have significant implications for the development and improvement of drinking water management programs and public health risk communication. For instance, poverty, poor perceptions and insecurity of drinking water are associated with higher consumption of tap water substitutes, such as costly sugary beverages and bottled water; this aggravates related diseases such as diabetes and obesity in Indigenous communities. ${ }^{15}$

A deeper understanding of how drinking water is perceived and how it can be supplied must be gained in ways that respect the history and culture of the community being served. Considerable survey research has been carried out to investigate the concerns and attitudes of Aboriginal people about environmental water. ${ }^{2}$ There is often an inherent, but untested, assumption that the provision of environmental flows to meet aquatic ecosystem requirements protects water interests for Aboriginal people. In 2011, the National Water Commission found that most jurisdictions had improved their consultation with Indigenous communities, but they had failed to develop effective strategies for incorporating Aboriginal social, spiritual and customary objectives in water plans. ${ }^{9}$

In Trout Lake, Canada, the development of a water consultation tool to better account for, and improve, the articulation of community water values (material, relational and subjective) during consultation processes was identified as the most useful application of the water value information gathered from community interviews. ${ }^{5}$ A water consultation tool is a record of communities voices on water interests, to formulate and communicate a clear message during consultation processes relating to water. ${ }^{5}$ The tool helps to evaluate the amount of attention that a community places on a water governance issue, to accurately account for community members' water values in decision making about drinking water policy. ${ }^{5}$ Water suppliers' perception of the issue tends to overestimate consumer satisfaction and underestimate the level of importance consumers place on water safety. ${ }^{16}$ Acknowledging the value of Aboriginal people as affiliates in health issues supports best public health practice. ${ }^{16}$

Another important factor may be low levels of trust in government water providers, because of how communities have been treated and are currently being treated by governments. Issues about drinking water - for example, stories of intentional poisoning of drinking water supplies in the past - need to be better understood to support health programs in rural areas. When considering drinking water, people mostly prefer what they know, since it becomes the custom and the standard by which quality factors are judged. Factors such as hardness, taste, colour and odour influence perceptions of risk and quality. Mobility does not appear to influence perceptions of safe water, but, in the First Nations of Canada, regional variations were found in perceptions of safe water, by urban, rural, provincial and territorial divide, as well as intra-Aboriginal diversity. ${ }^{1}$ Communities with poorer wellbeing were more concerned about the safety of their drinking water than communities with moderate wellbeing. ${ }^{1}$

Halpern-Felsher and colleagues argued that increased contact and familiarity with a hazard is associated with individuals becoming desensitised and habituated to its presence, so that risk judgements reflect behavioural experiences. ${ }^{17}$ The risks that accompany hazards become normalised and are consistent with "the normalisation of risk". Variations of risk and experience are likely to occur across Australian Aboriginal communities that 
represent a variety of contextual and institutional factors at the community level. Thus, the consumption of water of unknown quality such as rainwater instead of treated town water in Australian Aboriginal communities may be a community custom rather than part of a culture or a lack of trust in government water suppliers.

\section{Closing the Gap}

In many isolated Aboriginal communities where ongoing water safety is a pressing social issue, perceptions may be different from those in larger communities that are supplied with safe town water that is highly regulated and monitored. Even in communities with supplies that meet the Australian drinking water guidelines, researchers have found that an isolated incident of water quality failure in the past could create long-lasting suspicion towards the water. A crucial objective of the Australian Government's Closing the Gap in Indigenous Disadvantage program is to improve Aboriginal health to achieve morbidity and mortality rates similar to those for non-Indigenous Australians. Closing the Gap is a formal commitment developed by the Australian Government to reduce Indigenous disadvantage with respect to life expectancy, child mortality, access to early childhood education, educational achievement and the achievement of Indigenous health equality within 25 years. ${ }^{18}$ One sure way to support improved health outcomes of Aboriginal communities is to address drinking water quality and sanitation.

Illness related to drinking water contamination can lead to substantial morbidity, mortality, community anger and detrimental economic impacts. ${ }^{19}$ Safe water supplies present a significant challenge, because communities may prefer untreated water sources, such as rainwater, to town water that meets the Australian drinking water guidelines. Service providers and communities can work together to generate better understanding of, knowledge of, and solutions to, drinking water problems. These partnerships are a way of ensuring that the services are responsive to community needs, are conducted in a culturally appropriate manner and are beneficial to the community. ${ }^{20}$ Aboriginal people bear the knowledge and some of the responsibility to care for the waters upon which they depend for survival.

\section{Conclusion}

A new perspective on drinking water for rural Aboriginal communities is needed by public health authorities and drinking water providers. Research with Aboriginal communities to develop a deeper understanding of community norms, customs and perceptions relating to drinking water is crucial to support needs for cultural environmental water and drinking water. Water is an intricate part of life that has immense social, cultural and economic importance. Reducing public health risk due to drinking water of unknown quality will help to close the gap. Governance of drinking water in Aboriginal communities cannot be comprehensive without active engagement of the communities involved, and greater understanding of cultural issues, perceptions and behaviours towards drinking water quality. Understanding environmental water needs alone is not enough to close the gap.

\section{Competing interests}

None declared

\section{Author contributions}

FGJ designed and wrote the manuscript. PDM and $J J$ edited the manuscript. JA and NA edited the manuscript for cultural appropriateness.

\section{References}

1. Spence N, Walters D. "Is it safe?" Risk perception and drinking water in a vulnerable population. Water and Indigenous Peoples. The International Indigenous Policy Journal. 2012;3(3):9.

2. Jackson S, Robinson C. Indigenous participation in water planning and management, Northern Australia. Canberra: Northern Australia Land and Water Science Review; 2009.

3. Willis E, Pearce M, McCarthy C, Ryan F, Wadham B. The provision of water infrastructure in Aboriginal communities in South Australia. Canberra: ANU Press Library; 2009 [cited 2013 Oct 18]. Available from: press. anu.edu.au/apps/bookworm/view/Aboriginal+History+Vol ume+33/9921/ch07.html

4. Water-Culture.org. Indigenous Water Issues. Santa Fe: Water-Culture Institute; [cited 2015 Dec 09]. Available from: www.waterculture.org/IndigenousWater.html

5. Carter B. Water and social well-being in the Northwest Territories. Waterloo, Ontario: University of Waterloo; 2014 [cited 2014 Oct 2]. Available from: uwspace. uwaterloo.ca/bitstream/handle/10012/8824/Carter_Blair. pdf?sequence $=1$ \&isAllowed $=\mathrm{y}$

6. Syme GJ, Hatfield-Dodds S. The role of communication and attitudes research in the evolution of effective resource management arrangements. In: Hussey K, Dovers S, editors. Managing water for Australia: the social and institutional challenges. Collingwood: CSIRO Publishing; 2007:11-22.

7. Dunn G, Bakker K, Harris L. Drinking water quality guidelines across Canadian provinces and territories: jurisdictional variation in the context of decentralized water governance. Int J Environ Res Public Health. 2014;11(5):4634-51. 
8. Jackson SE, Palmer LR. Modernising water: articulating custom in water governance in Australia and East Timor. The International Indigenous Policy Journal. 2012;3(3):Article 7.

9. National Water Commission. Position statement: Indigenous access to water resources. Canberra: Australian Government; 2012 [cited 2015 Mar 2]. Available from: www.nwc.gov.au/_data/assets/ pdf_file/0009/22869/Indigenous-Position-StatementJune-2012.pdf

10. Neville L, McAnulty J. Communicable enteric disease surveillance, New South Wales, 2000-2002. N S W Public Health Bull. 2004;15(1-2):18-23.

11. De Guzman A, de Los Reyes VC, Sucaldito MN, Tayag E. Availability of safe drinking-water: the answer to cholera outbreak? Nabua, Camarines Sur, Philippines, 2012. Western Pac Surveill and Response J. 2015;6(3):12-16.

12. Walters D, Spence N, Kuikman K, Singh B. Multibarrier protection of drinking water systems in Ontario: a comparison of First Nation and non-First Nation communities. The International Indigenous Policy Journal. 2012; 3(3):8.

13. McLeod L, Bharadwaj L, Waldner C. Risk factors associated with the choice to drink bottled water and tap water in rural Saskatchewan. Int J Environ Res Public Health. 2014;11(2):1626-46.

14. Baird J, Carter B, Cave K, Dupont D, General P, King C, et al. Gaining insights about water: the value of surveys in First Nations communities to inform water governance. Indigenous Policy Journal. 2013;23(4):1-18.
15. Sarkar A, Hanrahan M, Hudson A. Water insecurity in Canadian Indigenous communities: some inconvenient truths. Rural Remote Health. 2015;15(4)3354.

16. Mackey E, Davis J, Boulos L, Brown J, Crozes G. Consumer perceptions of tap water, bottled water, and filtration devices. London: IWA Publishing; 2004.

17. Halpern-Felsher BL, Millstein SG, Ellen JM, Adler NE, Tschann JM, Biehl M. The role of behavioural experience in judging risks. Health Psychol. 2001;20(2):120-6.

18. Department of Families, Housing, Community Services and Indigenous Affairs. Closing the gap on Indigenous disadvantage: the challenge for Australia. Canberra: Commonwealth of Australia; 2009 [cited 2014 Jun 15]. Available from: www.dss.gov.au/sites/default/files/ documents/05_2012/closing_the_gap.pdf

19. Byleveld PM, Deere D, Davison A. Water safety plans: planning for adverse events and communicating with consumers. J Water Health. 2008;6(S1):1-9.

20. Massey PD, Pearce G, Taylor KA, Orcher L, Saggers S, Durrheim DN. Reducing the risk of pandemic influenza in Aboriginal communities. Rural Remote Health. 2009;9(3):1290.

\section{Copyright: (c) (i) (2)}

(C) 2016 Jaravani et al. This article is licensed under the Creative Commons Attribution-NonCommercial-ShareAlike 4.0 International Licence, which allows others to redistribute, adapt and share this work non-commercially provided they attribute the work and any adapted version of it is distributed under the same Creative Commons licence terms. See: www.creativecommons.org/licenses/by-nc-sa/4.0/ 